\title{
De cuerpos-territorio y disidentificaciones lesboeróticas. Las encrucijadas subjetivas en la narrativa de Yolanda Arroyo Pizarro
}

Of bodies-territory and lesboerotic disidentifications.

The subjective crossroads in the narrative of Yolanda Arroyo Pizarro

Diego Falconí Trávez

Universidad San Francisco de Quito /

Universidad Autónoma de Barcelona

DOI: https://doi.org/10.32719/13900102.2018.44.8

Fecha de recepción: 26 enero 2018

Fecha de aceptación: 22 marzo 2018

Licencia Creative Commons

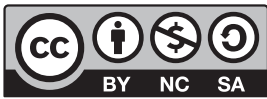




\section{RESUMEN}

El artículo busca, desde el vértice entre estudios de género y teorías pos/decoloniales, examinar elementos claves en torno a la narrativa de la puertorriqueña Yolanda Arroyo Pizarro que permiten entender la construcción de subjetividades a través de diversos escritos en los que raza, clase, colonialidad y deseo sexual se tensan de manera constante; tanto que, en ocasiones, articulan proyectos político-estéticos que parecerían contradictorios y que sirven para entender ciertas encrucijadas identitarias contemporáneas. Al hilo de esta hipótesis, se analizará en este ensayo tanto la perspectiva anti-racista así como la queer/cuir de la autora, buscando entender su compleja enunciación así como las varias imposiciones y resistencias de ciertas mujeres en la zona del Caribe.

Palabras Clave: Yolanda Arroyo Pizarro, literaturas queer, teoría cuir, antirracismo, lesbianismo, literatura caribeña, disidentificaciones.

\section{ABSTRACT}

This article intends to, from the vertex between gender studies and post/decolonial theories, examine key elements regarding the narrative of Puerto Rican author Yolanda Arroyo Pizarro which allow understanding the construction of subjectivities through various writings in which race, class, coloniality and sexual desire are constantly tensed; to the extent that, sometimes, they articulate political-aesthetic projects that seem contradictory and that serve to understand certain contemporary identity crossroads. In line with this hypothesis, this essay analyzes both the anti-racist as well as the queer perspective of the author, trying to understand her complex enunciation and the various impositions and resistances of certain women in the Caribbean.

KEYWORDS: Yolanda Arroyo, queer literatures, cuir theory, anti-racism, lesbianism, Caribbean literature, disidentificacions.

La literatura de Yolanda Arroyo Pizarro (Guaynabo, 1970) permite comprender una serie de temas y motivos fundamentales para la literatura escrita por mujeres en el siglo XXI en América Latina. Más aún, en sus textos narrativos la puertorriqueña, quien transita entre la escritura literaria y el activismo en la isla, ${ }^{1}$ logra articular una serie de discursos críticos que, aunque lejanos al panfleto, derraman en el papel posicionamientos políticos claves para la construcción subjetiva contemporánea.

1. Yolanda Arroyo Pizarro, junto con su compañera Zulma Oliveras Vega, fue la primera pareja de mujeres en casarse en Puerto Rico, después de la declaración de inconstitucionalidad de la Corte Suprema de EE. UU., que también se aplicó en la isla. Su activismo por el matrimonio igualitario, la crítica antirracista y la lucha contra la discriminación es bastante conocida en su país. 
Pondré especial atención en una faceta de la rúbrica autorial arroyana: la de la construcción de subjetividades diversas y aparentemente contrapuestas que, en diversos textos, encarnan proyectos estéticos complejos en los que raza, clase y deseo se tensan de manera constante. Para ello, y en primer lugar, me centraré en la perspectiva anti-racista como forma de reconstrucción corporal de la memoria en uno de sus trabajos; para luego abordar cómo la posibilidad del erotismo queer/cuir aparece difuminada en buena parte de su prosa; y concluir con una breve apreciación que permite entender algo del lugar de enunciación autorial de Yolanda Arroyo Pizarro. Para este análisis, afincado en los estudios de género, utilizaré la novela Caparazones (2010); los libros de cuentos las Negras (2012) y Lesbianas en clave caribeña (2012); y el diario personal/bitácora La Macacoa (2011).

\section{HACIA UNA MEMORIA GESTUAL DEL CUERPO COMO TERRITORIO. EL FEMINISMO ANTIRRACISTA EN las NEGRAS}

A pesar de que en buena parte de la obra de Arroyo Pizarro existen personajes, espacios y tiempos que permiten la articulación de acciones e historias en torno a la afrodescendencia caribeña, creo que hay un trabajo que merece especial atención. Me refiero al libro las Negras en el que, a través de relatos ficcionales cuyas protagonistas son mujeres negras, se busca hacer una reconstrucción de la dolorosa esclavitud en el Caribe. Este texto se convierte, así, en una reedificación del terror, pero también en un archivo de las posibles transgresiones llevadas a cabo para sobrellevar la brutalidad del régimen.

las Negras está compuesto por tres relatos "Wanwe", "Matronas" y "Saeta" en los que se narran diferentes formas de opresión/resistencia de las mujeres negras esclavizadas en el Caribe. El libro, justamente, comienza con un largo epígrafe de Guillermo A. Baralt, proveniente de su libro Esclavos rebeldes. Conspiraciones y sublevaciones de esclavos en Puerto Rico (1795-1873) que da cuenta no solo de un deseo de reciclaje de los recursos de la historia a través de la ficción (cuestión que otorga al libro un sabor testimonial), sino también de la mencionada tensión entre yugo y rebeldía 
que presenta a lo largo de sus páginas. Analizaré, con algo de detenimiento, los tres cuentos insertos en las Negras para poder desmenuzar una serie de propuestas y tensiones insertas en este libro.

En el primer relato "Wanwe" se aborda -nunca mejor dicho- el violento rapto de un grupo de mujeres africanas que son trasladadas al Caribe en una infame embarcación. A través de constantes analepsis, no obstante, se vuelve al espacio y la vida africana, caracterizada por una serie de rituales femeninos en una sociedad en la que las actividades públicas, como por ejemplo la caza, correspondía a las mujeres. De esta forma, el cuento, narrado en tercera persona, permite contrastar la vida en un matriarcado en África, contrapuesto al violento patriarcado impuesto por los colonizadores europeos. Para marcar este antagonismo escojo tres escenas del relato. En la primera se describe, a través de un flashback, el ureoré, rito lúdico en el que "las niñas que se han criado unidas, como hermanas, duermen pegaditas una de la otra, formando una hilera que une a cada cual por el área de los hombros [...] el juego de los hombros es un juego de féminas, prohibido a los machos" (Arroyo Pizarro "Wanwe" 2012a, 35). Esta exposición, en la que se combinan intimidad y complicidad, da paso al presente narrativo que se desarrolla en el espacio de la embarcación:

Las colocan acostadas, unas cerquitas [sic] de las otras en el sótano del barco. Tan pegaditas como si fueran a jugar ureoré. Wanwe mira a sus dos compañeras de hombros, una a la derecha y otra a la izquierda. Todas respiran con el mismo espanto y vacilación.

Entran hombres a aquel lugar tan oscuro y tan encajonado en la parte inferior de la barcaza, con órdenes de marcar con fuego a todas las cautivas. Usan unas letras de hierro caliente, con las iniciales de quienes seguro pasarán a ser los nuevos dueños (53).

Esa oposición, posible solo a través de la práctica corporal que cambia de significado dependiendo del contexto, revela una crítica hacia la violencia inserta en la historia colonial que va marcando los cuerpos de las mujeres negras no solo por su género sino también por su raza. En este sentido, si bien los raptos de las mujeres en varios textos europeos de diferentes épocas son de extrema violencia, dando cuenta de un canon artístico que naturaliza y estetiza estas acciones (Pollock 2007, 169), me parece que la contraposición corporal que plantea Arroyo Pizarro resulta básica para entender cómo el cuerpo de la mujer negra, al esclavizarse, encuentra 
un lugar de extrema indignidad en la economía de las representaciones de violencia contra la mujer.

En "Wanwe" hay una segunda escena que ejemplifica esta cuestión. Una de las mujeres intenta escapar del barco que la transporta hasta tierras americanas por lo que es atada y sumergida en el mar por parte de sus captores, aparentemente para ser ahogada. No obstante, luego aparece el verdadero deseo de castigo fatal pues poco después ella "es levantada por los pies como una guerrera de alabastro que parece inmortalizarse, su cuerpo ya ha sido partido a la mitad por los mordiscos de los tiburones" (Arroyo Pizarro 2012a, 58). El cuerpo desmembrado de la mujer que, como una estatua, se desea "inmortalizar" por parte de los colonizadores en la retina del resto de mujeres presentes en el barco, dibuja un rapto con una estetización muy diferente al de la épica masculina en perímetro europeo, bajo, por ejemplo, la plantilla de Helena de Troya en La Ilíada, texto que se esparce intertextualmente en múltiples archivos literarios, pictóricos o escultóricos. Así, en "Wanwe" el cuerpo de la mujer no se representa solo como denigrante forma de intercambio masculino en época de negociación, guerra o conquista, sino que ese cuerpo de mujer racializada, pierde todo posible sentido de humanidad a través de múltiples mecanismos: la tortura, la numeración sobre la piel, el asesinato, la deformación del cuerpo muerto, incorporando así una serie de violencias que azotan a la corporalidad femenina y que permiten afirmar la hipótesis de la "colonialidad del ser”, desarrollada por Nelson Maldonado Torres; es decir, una práctica desarrollada en la modernidad que para desubjetivar a la alteridad colonizada apela "a la normalización de eventos extraordinarios que toman lugar en la guerra. Mientras en la guerra hay violación corporal y muerte, en el infierno del mundo colonial la muerte y la violación ocurren como realidades y amenazas diarias" (2007, 148; cursivas en el original). Este tratamiento de guerra contra la mujer negra en el régimen colonial americano, en suma, la diferencia de modo preciso respecto a las mujeres occidentales.

Sin embargo, en la última escena que busco abordar de este primer cuento -en la que se mezclan, otra vez, las historias pasada y presente, la africana y europea- se abren sutiles posibilidades para salir del horror de la violencia colonial. Una nueva analepsis nos transporta al momento en que Wanwe es aprisionada en África. Segundos antes de su captura se escucha un silbido. Pertenece a su madre, la cazadora experimentada del grupo, que a través de ese gesto alertaba a las demás de la llegada de un animal 
peligroso; en este caso, el hombre europeo que rapta a las mujeres de la tribu. En el desenlace del relato, aún en altamar, se escucha otra vez la seña materna: "por primera vez desde que Wanwe deja la selva vuelve a oír el silbido" (59); poderoso sonido de cuerpo, que marca un final incierto en el que no se sabe si la madre está también prisionera en el barco, si es un recuerdo de la protagonista o si ha vuelto, en un guiño fantástico, para proteger a la mujer del esclavizador, pero que, de cualquier forma, permite representar las reacciones ante el horror colonial sobre el cuerpo de la mujer negra. Final que permite ver la antítesis entre el pasado africano perdido y la nueva realidad colonial en otras tierras caribeñas.

"Matronas", el segundo relato de las Negras, narrado en primera persona, cuenta la historia de Ndizi, una mujer que está en una celda por haber sido acusada, junto con otras esclavas, de "desobediencia, conducta desafiante, insolencia, vagancia excesiva, incitación a revueltas y, en última instancia, las fugas" (Arroyo Pizarro 2012a, 89). En ese terrible espacio sufre de múltiples torturas; la más dramática, una serie de violaciones sistemáticas que dan cuenta del ultraje fálico del régimen esclavista. Por ejemplo, ella detalla: "el capataz y el sereno vuelven a golpearme, a amarrarme y a penetrarme con sus penes rancios” (71). Sin embargo Ndizi se defiende constantemente de sus agresores. De hecho esta es la quinta celda donde ella es instalada pues en una anterior, por mencionar un caso, mordió el pene del sereno que abusaba sexualmente de ella. Esa acción de defensa ante la vehemente invasión corporal, además, desembocará en un escape de las demás mujeres prisioneras, cuestión que hace que sea percibida como más peligrosa.

En esta línea de opresión/resistencia que debe generar narraciones opuestas que necesariamente se encuentran, cabe mencionar que si en "Wanwe" la contraposición del relato se articulaba temporalmente (pasado africano/presente colonial) este segundo texto busca que la antítesis se lleve a cabo a través de dos personajes: Ndizi y Petro. Este último es un sacerdote que visita en su celda a Ndizi y que, a través de la confesión como sacramento y no como medio judicial, busca entender las acciones de la mujer. Con tal fin, él le garantiza a Ndizi que no contará nada de lo que le diga en el proceso jurídico aunque en realidad ese secreto no busca "salvar su alma" o perdonar sus pecados sino que lo que intenta "es saber, documentar esta violencia, esta histórica bestialidad. Hay frailes en las otras islas escribiendo crónicas sobre los eventos; yo quiero narrar 
este. Nos hacemos pasar por colaboradores de la corona" (Arroyo Pizarro "Matronas" 2012a, 81). Ndizi, a pesar de la confesión de su confesor, es desconfiada y le relata algunos pocos agravios que permiten entender que sus ataques son en verdad formas de defensa. Solamente cuando conoce su condena a la horca decide confesar su controversial crimen que ella realiza para salvar a los bebés negros que nacen bajo el cruel estado colonial:

Los ahogo en el balde de recolectar placentas, padrecito. Presiono sus negras gargantitas con mis dedos y los sofoco. O los asfixio con sus cordones umbilicales, incluso maniobrando antes que salgan del vientre. La madre no se da cuenta, o lo prefiere, o lo ha pedido [...] El acto, que puede ser muy sutil, pasa desapercibido por el velador de recién nacidos, que vigila procurando la sobrevivencia del futuro esclavo. Lo burlo. Lo burlamos. [...] No soy la única. Muchas me siguen. Hemos logrado un ejército (Arroyo Pizarro 2012a, 94).

De esta manera, Ndizi con su testimonio deja, por escrito, el acto transgresor ante la ley. Se convierte en una antiberoina, una justiciera, que al dudar de la palabra europea, trunca el proyecto de Petro de construir, desde su crónica, un argumento de bondad e indefensión negra, similar al del Padre las Casas (quien, de hecho, aunque denunciaba la esclavitud de las personas indígenas, defendía -o en el mejor caso, no cuestionaba- la de las personas negras, lo cual no deja de ser una posible crítica). En otras palabras, Ndizi con su testimonio desnuda los propios límites éticos de la resistencia, que solamente pueden entenderse en un régimen deshumanizante y absolutamente falto de ética como fue el colonial.

Siguiendo con el antagonismo entre protagonistas, es curioso que en este relato donde Petro simboliza lo letrado, en un territorio liminar que junta lo jurídico con lo literario, la protagonista, narradora intrahomodiegética, simbolice la voz. Digo esto, pues Ndizi paulatinamente va olvidando las palabras en su idioma (yoruba) y adquiere otras expresiones en castellano. Además, ella comenta: "puedo recitar algo así como un himno entonado por los holandeses, un tipo de cántico en el que desprecian a la tierra denominada Francia" (Arroyo Pizarro "Matronas" 2012a, 67). En este aprendizaje, además, la protagonista sabe "un poco de las lenguas de los nativos, aquellos que los blancos llaman taínos y escasean” (66), cuestión que permite rescatar algo de la voz nativa, exterminada en el Caribe. Esta caracterización, que nos ubica ya no en el viaje colonial sino en 
la adaptación a una nueva tierra, posibilita entender una identidad fluida, marcada por la travesía, por las colonizaciones culturales, por los rasgos identitarios originarios; por la búsqueda, en definitiva, de una propia habla que no tiene ni la seguridad ni la fuerza del locus masculino del control del cuerpo de la mujer que tiene Petro, pero que sobrevive estratégicamente a la colonialidad.

El tercer y último relato de las Negras es "Saeta" que narra la historia de Tschanwe, otra mujer esclavizada, aunque ahora las acciones se trasladan al espacio privado del "amo", la casa del conde don Georgino Pizarro, un amante de la caza deportiva. El recinto hogareño no resta las vejaciones sexuales y de otra índole que vuelven a atentar contra la dignidad corporal de las mujeres esclavizadas. A raíz de la súbita muerte del pero de caza de la familia (que recibe muchos más lamentos que las personas negras muertas) la protagonista descubre que es una saeta incrustada en el vientre del animal la que lo ha matado; a partir de ello explora un artefacto, la flecha como arma capaz de infringir daño y muerte al cuerpo. Ella, a escondidas, practicará disparar con la ballesta en un descampado para entender la lógica de ese instrumento. Los hijos del conde Pizarro, sin embargo, descubren un día sus acciones y deciden asustarla. La acorralan y empiezan a torturarla con las puntas de las flechas, a herirla de un modo sádico e inhumano, tal como muestra el fragmento citado a continuación: No se detienen. Continúan espetando los filos. Estos entran y salen sin compasión. Los senos, el cuello, el abdomen de la esclava se marcan de rayas como tatuajes. Los tatuajes hacen correr el líquido cálido, le hacen caer de rodillas debilitada" (Arroyo Pizarro "Saeta” 2012a, 123). En ese momento, Tschanwe saca la saeta que encontró en el cuerpo del animal y que llevaba escondida y lastima a uno de los hijos del amo. Por ese agravio, que sería en estricto derecho una legítima defensa, recibirá una brutal golpiza a manos del conde Pizarro y de otros hombres que terminarán matándola. A pesar de la fatalidad de su desenlace, hay una estrategia narrativa interesante, la de la trama encadenada, que permite dar un giro a la/su historia.

Efectivamente, a lo largo del cuento se narra una trama paralela en la que en el presente -y no en el pasado, como sucedía en "Wanwe"- se menciona al pueblo de la protagonista, el Namaqua, ubicado al sur de África. En esta otra dimensión narrativa, Tschanwe obtiene una vida distinta, no solo porque vuelve a tener la dignidad arrebatada sino porque, a través de un giro fantástico, se le concede la posibilidad de resistir al dolor 
y a la muerte. Así, cuando ambos planos narrativos se encuentran, Wanwe a la vez que agoniza logra escapar inexplicablemente de sus agresores, "se embadurna de pinturas bélicas [...] [y] la voluntad de sus ancestros y su temple la dirigen de vuelta por el túnel” (Arroyo Pizarro "Saeta" 2012a, 127). Al final del relato, el cuerpo de la protagonista desaparece del espacio del latifundio colonial. Desaparece también una de las ballestas del amo. Cuando los hombres inquietos por estos sucesos van a la floresta a ensayar sus tiros, una "saeta disparada a través de la arboleda al final del llano emite un silbido", (130) que terminará en la frente del conde don Georgino Pizarro. Esta escena más que articular una noción de justicia ensambla, desde lo fantástico, una idea de defensa en el ataque. El silbido así se convierte, como sucedía en el relato de "Wanwe", en el modo esperanzador de resistencia. De este modo, con el uso de este intratexto, el del silbido, las Negras se convierte en un proyecto circular en el que el infortunio de Wanwe (y todas las mujeres que llegaron detrás de ella) logra ser efectivamente vengado por Ndizi.

Me he detenido en los relatos, haciendo énfasis en las descripciones explícitas de la violencia contra los personajes de estas mujeres negras así como en sus agudas resistencias, porque me parece que la autora tiene un proyecto particular: el de proponer al cuerpo en tanto que "territorio político” (Gómez Grijalba 2012). Es decir, y en palabras de Dorotea Gómez Grijalva, el cuerpo como un topos "con historia, memoria y conocimientos, tanto ancestrales como propios de [... ] [una] historia personal" (6). Esta caracterización, que se mueve entre diferentes emplazamientos coloniales (la embarcación, la prisión, el latifundio) y que encarna a una serie de mujeres, no se queda, pues, con esa impávida metáfora colonial tan usada por la novela latinoamericana: la del territorio ocupado como “innominado y virgen” (Aínsa 2003, 29), que terminaría ratificando un tropo estático de dominación. Por el contrario, el de Arroyo Pizarro es un rescate de esa memoria espaciotemporal, en la que el cuerpo violentado de la mujer negra, no originaria del Abya-Ayala, y sin capacidad de escribir su propia historia en el código colonial, narra el devenir territorial/subjetivo usando al espacio-cuerpo como un lugar de agenciabilidad en el que se intenta decolonizar al ser.

Por ello es que Wanwe regresa al poder erótico y cómplice del cuerpo femenino africano que se contrapone a la carnicería mercenaria de los conquistadores; que Ndizi personifica una defensa desesperada pero tam- 
bién la riqueza y la creatividad de la oralidad; en un espacio de supervivencia y disputa, cuestión que se enfrenta a la rigidez de la letra jurídica y literaria del sacerdote-cómplice europeo; y que Tschanwe, gracias a múltiples artificios espirituales, contraataca al hombre blanco con el único motivo de defenderse y de buscar algo de justicia. La propuesta de la autora, en consecuencia, es que solo cartografiando al cuerpo de la mujer negra esclavizada y desangrando un territorio como el Caribe, es posible entender el proyecto colonial racista y la crítica que hoy en día permite denunciar sus profundas bases ideológicas.

En tal virtud, cabe señalar que para articular al cuerpo como territorio político además de las posibles fuentes históricas es importante acudir a otros registros, como el lenguaje corporal. Me parece que Arroyo Pizarro, por ejemplo, apela al gesto como forma de reconstrucción de la memoria. Efectivamente, y siguiendo los postulados de Juana María Rodríguez, el gesto "excede el lenguaje a través del lenguaje, es extender los brazos para tocar figuras en movimiento que ya no están allí, es capturar con marcas estáticas en blanco y negro el olor de un cuerpo que no ha dejado rastro" $(2016,33)$. Transcribir el gesto es entonces una tarea que vuelve a lo abyecto del cuerpo como seña identitaria (Kristeva 1985) y que permite pensar en cuerpos y territorios pasados por alto a través de, en este caso, algunas narradoras y personajes que al escribir con sus cuerpos reescriben la historia (pos)colonial. Es por ello que los silbidos, mordiscos, asfixias, cuchilladas devueltas y flechazos son, a mi parecer, los gestos fundamentales en las Negras, pues redibujan lugares y sujetos complejos que en la revisión actual del canon de representación de la mujer negra, disputan un lugar particular y crítico, tanto con el heteropatriarcado pero también con otros feminismos, para la mujer negra latinoamericana. Con esto quiero decir que lo que me parece más relevante de este libro, no es solamente "la valoración y reconocimiento de los trabajos ejercidos por las mujeres negras en América, donde han sido comadronas, curanderas, yerberas, sobadoras, nodrizas, santiguadoras, cuenteras, sirvientas, cocineras, ordeñadoras de vacas, etc." (Ramos Rosado 2012, 189), sino entender, gracias al uso del gesto como custodio de la memoria, qué proyectos políticos y estéticos actuales aparecen en él y que lo diferencian de otros anteriores.

En este sentido, el pensamiento negrista, tan importante para algunas regiones latinoamericanas, entre ellas el Caribe, gracias a las propuestas contraideológicas y negristas de Aimé Césaire, Franz Fanon, Ni- 
colás Guillén o Manuel Moreno Fraginals, de imposible abordaje en estas breves líneas, articulan una crítica en contra del euro-centrismo pero con miope perspectiva sexo-genérica. Asimismo, el feminismo negro, afincado en Estados Unidos, tan importante para la subjetivación de la mujer más allá de una visión blanca y burguesa, con nombres como los de Audre Lorde, 2 Angela Davis o Bell Hooks, a pesar de algunos guiños con los movimientos anticoloniales, no logró captar todas las propuestas revisionistas a favor de América Latina. Me parece, en cambio, que es otro proyecto contemporáneo el que permite leer mejor la propuesta escritural de Arroyo Pizarro a través del cuerpo como territorio político. Me refiero al feminismo antirracista que, gestado en América Latina en la última década, ha permitido articular un aparataje crítico donde los discursos emancipatorios de género, raza y decolonialidad se encuentran desde una crítica situada. Efectivamente, tal como menciona la teórica dominicana Yuderkys Espinosa-Miñoso esta rama del feminismo realiza un "análisis de la colonialidad y del racismo -ya no como fenómeno sino como episteme intrínseca a la modernidad y sus proyectos liberadores- y su relación con la colonialidad del género", poniendo en duda incluso "la pretensión de unidad en la opresión entre las mujeres" $(2014,12)$. En suma, que el feminismo antirracista se filtra en las páginas de la autora puertorriqueña quien, a su vez, ayuda a alimentar, desde su prosa, a esa sugerente crítica contemporánea. Esto da cuenta de una escritura política en la que antirracismo y decolonialidad se entremezclan para reconstituir al sujeto mujer y en la que la memoria de una resistencia se reconfigura a través de otros lenguajes del cuerpo.

2. Esto a pesar de que las Negras incorpora, literalmente, textos de una de las pensadoras más importantes del feminismo negro estadounidense, Audre Lorde, por lo cual hay un diálogo intertextual. Sin embargo, el posicionamiento de la realidad colonial de las mujeres negras puertorriqueñas avant la lettre, da cuenta de otro tipo de sensibilidad y de época al momento de pensar las subjetividades contemporáneas. He trabajado la relación de Lorde en la obra de Arroyo Pizarro en el artículo "Puerto Rico erizando mi piel. Intertextos/intercuerpos lordeanos en la narrativa de Yolanda Arroyo Pizarro", citado en la bibliografía de este ensayo. 


\section{AMORES LÉSBICOS, AMORES QUEER: SOBRE DISIDENTIFICACIONES LESBOERÓTICAS Y SUBJETIVIDADES TÁCITAS EN CLAVE CARIBEÑ $A^{3}$}

La compleja crítica queer, gestada en la última década del siglo XX en Estados Unidos, en años recientes ha tenido productivos debates y traducciones en América Latina. Puerto Rico, por su particular situación de ser parte de los Estados Unidos y también de América Latina, ha sido un sitio clave para las digresiones de la teoría y práctica queer $/$ cuir. $^{4}$ Así, un particular flujo de ideas que permitió incorporar lo queer de modo más veloz y, acaso, menos traumático que en otras naciones o regiones de América Latina es algo que no se puede ignorar al momento del análisis regional.

Esta teorización queer -que más que articular categorías cuestiona la propia categoría como forma única de subjetivación- ha permitido problematizar ciertas cuestiones: la fluidez identitaria, la performatividad corporal, la crítica a la normalización LGBTI, la incorporación de matrices subjetivas ignoradas por ciertos movimientos sexo-diversos, entre otras; sin que esto signifique, de ninguna forma, que esta crítica no haya tenido detractores en el feminismo (De Lauretis 1994), los movimientos de la diversidad sexual (Halpering 2014) o la conjunción de estos en América Latina (Mogrovejo 2011). En todo caso, varias de estas tensiones de las traducciones queer han sido incorporadas en múltiples textos literarios de América Latina.

En un ensayo que evalúa las posibilidades de la teoría queer en América Latina, a partir del estudio de tres escritores maricas del canon regional, Paola Arboleda Ríos plantea una interesante duda: “¿qué le falta a lo queer para que se convierta en locura, al estilo latinoamericano, estilo Perlongher, Lemebel o Arenas? Le hace falta raza, clase, le falta realidad social y política, y, al parecer, le falta amor" (Arboleda 2011, 121). Me parece que el amor, entendido no como sentimiento universal sino como

3. Parte de las ideas de este acápite ha sido desarrollado en el artículo de mi autoría "Puerto Rico erizando mi piel. Intertextos/intercuerpos lordeanos en la narrativa de Yolanda Arroyo Pizarro".

4. Rescato el pensamiento de autorías académicas fundamentales como las de Arnaldo Cruz-Malavé, Larry Lafountain-Stokes, Rubén Ríos Ávila o Licia Fiol-Matta, por mencionar unos pocos. 
un discurso que vincula las prácticas eróticas, las ideologías políticas y la construcción identitaria, es un interesante punto de partida para evaluar la narrativa de Yolanda Arroyo que puede contener algunas de las claves que faltan -o que sobran-para comprender el aterrizaje queer en América Latina, desde ese particular vértice que es Puerto Rico. En este sentido, el lesboerotismo es una clave de lectura ineludible en la autora, pues las relaciones de amor entre mujeres aparecen prácticamente en todos sus trabajos aunque con una serie de coqueteos queer. Problematizar el amor, sus prácticas, sus construcciones, sus improntas, ha sido fundamental para entender la propia identidad lesbiana. De acuerdo a la explicación de Sheila Jeffreys:

han existido siempre [para el movimiento feminista lesbiano] unos valores compartidos: el amor de las mujeres; la necesidad de eliminar todas las jerarquías referentes al poder abusivo basado en el sexo, la raza o la clase; la necesidad de cambiar el mundo de manera radical y no sólo en los detalles, y la construcción de una la visión feminista lesbiana. En la controversia sobre la sexualidad, que causó la fragmentación de la comunidad lesbiana, fueron las voces de las lesbianas negras y judías las que se alzaron desde su amarga experiencia contra la opresión como fuente de placer. Audre Lorde afirmó, en respuesta al auge del sadomasoquismo lesbiano: "Como mujer perteneciente a una minoría sé perfectamente que el dominio y la sumisión no son temas propios del dormitorio" $(1996,254)$.

A la luz de estas palabras, ¿`cómo traducir esos diversos deseos del activismo lesbiano en los textos literarios? ¿Puede contradecirse ese imperativo lesboerótico de sexualidad sin sumisión, que subrayaba la pensadora lesbiana y negra Audre Lorde, dependiendo de su contexto? ¿Es posible que ese amor lesbiano se junte, hoy, con prácticas disidentes queer que desordenan las categorías LGBTI? Creo que esas preguntas posibilitan entender cómo la identidad lesbiana y la crítica queer pueden encontrarse a través de puestas en práctica del deseo en la narrativa actual.

Efectivamente, el lesboerotismo que Arroyo Pizarro dibuja en sus textos se comprende de prácticas complejas, llena de matices y contradicciones, que impiden ensamblar identidades fijas, mediadas por la clase, la etnia, la colonialidad y en los que el discurso de un amor ideal encalla o, en el mejor de los casos, adquiere otras posibilidades de relaciones duraderas. Así, un leit motiv que se repite en la obra de la autora y que se relaciona con esto es la dificultad de identificación total de las personajes lesbianas y 
las particulares relaciones que se generan, pues al parecer muchas veces hay una tercera persona (o entidad) que trunca esa idea de amor y en la que, a menudo, persiste un lugar de dominación lésbico.

"Chévere, un mafioso", relato del libro de cuentos Lesbianas en clave caribeña, cuenta, por ejemplo, la historia de una joven, la narradora del relato, que se relaciona con un pandillero, capo del barrio en realidad, llamado Chévere. Él es violento, asesina personas, atemoriza a otras, mantiene un harem de mujeres y controla la periferia de San Juan: su zona. A Chévere, personaje que encarna un poder patriarcal que es paralelo al Estado, "lo mordió el perro", es decir VIH, por lo que se articula una complejidad identitaria marcada por la marginalidad y la vida en riesgo. La narradora lo teme y aun así lo respeta. Esa reverencia se genera gracias a una joven llamada Ileana que despierta profundos deseos y sentimientos eróticos en la protagonista por ser una mujer bella y por su amor por la lectura (cosa que se evidencia pues ha leído toda La Ilíada).

Chévere entra de lleno en la trama cuando Ileana le confiesa a la narradora cómo su mamá lo contrató para que matase a su esposo, el padrastro de Ileana, por haberlo descubierto en las noches haciéndole a la joven “cosas terribles que no se pueden repetir" (Arroyo Pizarro 2012b, 95). Chévere asesina al padrastro abusador y da todo el dinero pagado por la mujer para que Ileana pueda ir a la universidad. Por ello, la narradora afirma que: "haberla conocido [a Ileana] y saber su historia, me hace sentir a gusto con la presencia que Chévere tuvo en mi entorno de crianza. Y eso es una cosa muy rara, que incluso hoy no puedo saber del todo" (96). Completa la inquietante trama el hecho de que la narradora termina siendo amiga de la joven y se besa con su novio a sus espaldas, a pesar de que ambas jóvenes nunca tuvieron ningún contacto erótico.

Esta compleja relación de poder, en la que el matón machista se convierte a los ojos de la adolescente lesbiana también en el "salvador" de la joven amada y maltratada, no deja de ser inquietante y da cuenta de un amor silencioso, marcado por violencias que coexisten: la del padrastro, la de Chévere, la de la madre de Ileana, la del VIH; todas pautas de la marginalidad que obliga a fundar un orden paralegal y que imposibilita pensar a la lesbiana del Caribe de modo sencillo. El amor entre mujeres que nunca se dice pero se profesa es, al final, el motor narrativo del texto; la supervivencia precaria y la dependencia de un tercero, en cambio, son 
subtextos que revelan las contradicciones que impiden ensamblar narraciones lesboeróticas ideales sino formas complejas de deseo y resistencia.

Similar cuestión ocurre en la novela Caparazones que cuenta la relación adúltera entre Nessa y Alexia, dos mujeres de mediana edad, insertas en el mundo laboral de una clase acomodada. Ellas, personas apasionadas, tejen un amor intenso, tematizado por los deseos de la carne y los viajes, cuestión que permite entender la constante alusión de las tortugas marinas en la obra. Sin embargo, su amor es puesto en entredicho por interferencias externas. Alexia está casada con David, un arquitecto, pero logra escaparse de modo continuo a casa de Nessa, que se convierte también en su hogar. David no es el único tercero que importuna la relación e impide la consolidación de esta. Una presencia fantasmagórica, una sombra que cito en el siguiente fragmento es parte de la vida de las mujeres:

Entonces Alexia se vuelve hacia mí y me mira enojada, como culpándome. Sí, me dice con sus ojos, que soy yo la culpable de que a la entidad que habita nuestro hogar, ella no le caiga bien. $Y$ es en momentos como este que la odio. Por hacerme sentir tan fuera de sitio, tan incomprendida. Y es ahí cuando deseo que en efecto la sombra no la quiera, no se sienta a gusto con ella (Arroyo Pizarro 2010, 116).

El tinte fantástico devenido de esta presencia sobrenatural, al parecer la abuela muerta de Nessa, no obstante, se naturaliza en sus vidas - un guiño con el realismo mágico-, y se convierte más que en un estorbo en un catalizador de la vida para ellas. Esto, si bien ratifica una mirada vigilante sobre sus cuerpos y acciones, en tanto que mujeres lesbianas, impide pensar un relato de amor fatal. Efectivamente, incluso cuando más adelante en el libro se descubre que una de las dos mujeres muere, la otra mujer queda embarazada y decide tener a ese bebé por su cuenta, lo cual posibilita entender nuevos modelos familiares. Acaso, esas figuras de carne y hueso (el marido) y aquellas no del todo explicables (la aparición), son maneras de enunciar que en ciertos contextos, más que identidades o instituciones familiares estables, existen caparazones, refugios en los que ir ejerciendo de modo diferente eso tan complejo que se define como amor.

De los muchos relatos de Arroyo Pizarro que siguen con este patrón de relación compleja, "Poliarmonía en el Caribe" me parece que estira al máximo la posibilidad del deseo lesbiano. La narradora, una joven lesbiana, comenta sus varias relaciones: 
Mi mujer, mi primer amor, me engañó con una compañera de trabajo. Lloré a mares, me quise suicidar, la vida dejó de tener significado. [...] Para subsanar la infracción, y prometiendo que no volvería a suceder, mi mujer incluyó en nuestra relación de cama al muchacho, también compañero suyo, que usábamos los fines de semana para engañar a mi familia, haciéndoles creer que yo me había ido a vivir con él como novios en vez de decirles la verdad sobre mi closet. [...] La novedad se volvió costumbre y dos años más tarde los tres criábamos a un baby, manejábamos responsabilidades de renta y préstamos [...] Vivíamos en Villa Carolina. Nada estorbaba nuestra pacífica existencia $(2012 b, 64)$.

Después de esa relación, la protagonista se queda en pareja con ese hombre al que inicialmente rechazaba. Su última relación, de la que queda constancia en el relato la mantendrá "con la zorra del Principito", por lo que no queda del todo claro con quién continuará su periplo de afectividad íntima. En este cuento, en el que nuevamente aparece el tercero que no inoportuna sino que es una oportunidad para entender el devenir del deseo, la narradora entiende el cambio de orientaciones sexuales y modelos familiares inherente en su vida. Por ello, de modo decidor concluye diciendo "nada ha cambiado" (65).

En otros relatos, como "Fahrenheit", vuelve a aparecer un tercero que es parte de la relación erótica y que, en este caso, se imagina. La narradora poco a poco va develando la explicación del sugerente título del cuento, que tiene que ver con el erotismo en contextos poscoloniales. "Bajaré la voz. Te llamaré Walter, y cerraré los ojos cuando te bese. Apagaré las luces cuando te frotes sobre mí y acaricies afanosamente mis pechos. Les contaré a mis amigas de tu Hombría” (2012b, 11). En este acto profundamente sensual, de cercanía e intimidad, empiezan a aparecer estratégicas omisiones que delinean poco a poco ciertas prácticas transgresoras en el acto sexual: "Me callaré el detalle de las manos. Tus manos como genitalia que me palpitan adentro y que me frotan los montes abultados afuera. Diré que me penetras fuertemente, como si pudieras” (11). Este resquebrajamiento del acto de penetración (¿pene-traición?) convencional, símbolo de la fuerza del heteropatriarcado, se sigue desarrollando hasta revelar el título del cuento que descubre también el escondite subjetivo:

Llevaré tu perfume de Hombre siempre en mi memoria. Esencia de macho posesivo de mí. Olor de tu cuello. Aroma Fahrenheit [...] Mentiré. Me mentiré con tus olores. No pensaré en todos los olores de tu cuerpo [...] Ignoraré 
tus pantallas, tus uñas largas pintadas, tu falda sobre la butaca. Me sumergiré en tu centro acalorado. Esconderé el secreto. (12)

En este interesante texto, el perfume de la marca Christian Dior revela un refugio secreto del lesbianismo a través del olor transnacional, unificador de masculinidades, que de algún modo da la pauta de cómo leer la disidencia sexual en Puerto Rico. El nombre Fahrenheit, que también sirve para la medición de calor en ciertos países anglo a través de ese sistema de medida, se utiliza en el cuento para simbolizar la candela erótica pero también esa extraña condición de país latinoamericano que es parte de Estados Unidos y que modifica sus temperaturas, en términos de ciudadanía. Todas esas tácticas se insertan en la creación de este tercero, un alter ego masculino escondido en la colonia, que sirve para entender extrañas formas de socialización, en las que la dominación está presente.

En los relatos abordados, el lesboerotismo, perímetro donde se negocia el amor entre lesbianas, convergen a menudo heteros oportunistas, matones seropositivos, maridos engañados, maridos desengañados, monigotes coloniales, e incluso fantasmas que, en definitiva, sirven para crear un ardid para la existencia lésbica. Dicho esto, ¿̨no será que existe en estos cuentos una traición a la lesbiana y su esmerada construcción para que no esté mediada por los heteropatriarcas? ¿No son estos personajes despolitizadores del deseo lesbiano periférico al admitir ciertas formas de dominación? ¿No defienden una vuelta al secreto y a la vergüenza a la cual se opone el orgullo (GLBTI)?

Respecto a esta última cuestión, fundamental para la politización de las identidades LGBTI, la teoría queer gestada desde voces latinas puede ser decidora. Respecto a la cuestión del secreto lésbico, Carlos Decena ha cuirizado -a partir de su estudio de hombres gays dominicanos diaspóricos- parte de la promesa surgida: que después de salir del closet y convertirse en un gay/lesbiana "de verdad" vendría la liberación subjetiva. Este "necesario" ritual de paso para convertirse en un gay y empezar una nueva vida, comenta el académico, caracteriza a las democracias liberales, lo que hace que no necesariamente sea el tipo de vida que desean todas las personas. Hay muchos sujetos sexo-diversos latinos que han inmigrado a Estados Unidos y que se convierten para sus familias en "sujetos tácitos"; es decir que, como el sujeto tácito en la lengua que está presente implícitamente en la oración a través de la conjugación del verbo, no necesitan 
del acto de salir del closet para seguir una vida. En este sentido el teórico comenta que "silencio no es igual a muerte", pues "la ambigüedad y los entendimientos compartidos son fundamentales para el sostenimiento de los individuos y las colectividades" (Decena 2014, 224). Esta compleja postura, que sin defender la homo/lesbofobia internalizada apela a diversificar los rituales de paso y a no universalizar conceptos como "privado", "familia" o "libertad", puede verse en los textos de Arroyo Pizarro que están marcados por la ironía y la supervivencia, y en los que el secreto es un escondite pero también una sutil parodia: un silencio que incluso puede volverse placentero y constructor de nuevos vínculos familiares en determinados lugares donde el liberalismo llega de modo discontinuo.

Así, sus textos no niegan a la lesbiana y a otras sexualidades presentes en el tráfico global de identidades, pero amplían sus posibilidades al negar una sola forma de identificación. En este sentido, José Esteban Muñoz, una de las voces de la llamada queer of color critique que se desarrolla en Estados Unidos en respuesta a una crítica queer blanca, proponía un interesante término: el de disidentificación, que de modo astuto mezcla las palabras desidentificación y disidente. "The disidentification, in this instance, is the construction of a lesbian heroine that changes the way in which the object is inhabitated by the subject" $(1999,28)$. Arroyo Pizaro disidentifica al personaje de la lesbiana "en clave caribeña", le da una inflexión particular que posibilita pensar cuestiones de clase, raza, colonialidad y que permite indagar sobre las posibilidades del cuerpo.

En esta línea, la autora rompe con la idea de un deseo lesbiano, que sea enteramente femenino, como el que esbozaban autoras como Monique Wittig (1977), y propone una suerte de "masculinidades femeninas" (Halberstam 2008) que deshilachen las prácticas sexuales y las identidades inmóviles. Por ejemplo, en el cuento "Asian Jelly" Choi le pide a su novia Nessa que, previo al acto sexual, siga sus órdenes, que vaya al mercado y compre mermelada, que se afeite, que la espere desnuda.

Cuando Choi llega, Paola siente el aroma de su perfume desde que ésta sube las escaleras. Cierra los ojos, obediente, concediendo así la penúltima de las instrucciones. Percibe que su amada mujer, recién mudada con ella, recién estrenando promesas de vida, se está quitando la corbata, está desabotonando camisa y pantalón, y se entera cómo baja con ansiedad la cremallera. Cuando escuche la orden que Choi prometió decir, deberá realizar el último paso. Acto seguido, Choi pronuncia: Ponte en cuatro, puta. [...] 
El círculo de su goloso ano se convierte en un verso de Neruda donde la primavera madura los cerezos. La lengua de Choi la penetra saboreando cada delicado margen. Aquella profundidad achocolatada, y nueva es una promesa de futuro. Ambas lo saben. Choi acerca su rostro, y comparte la savia recolectada. Besa de lengua, deleitosa. Muerde labios, nuca, mentón. Toma el cinturón y lo acomoda, exigente, en el cuello de Paola. La besa mientras cierra el círculo del aire, mientras la piel del cuello es una paleta de rojos matices. Sostiene con cuidado toda vez que la mujer temblorosa frente a ella, busca el mullido entorno de su propia cavidad. Uno, dos, tres dedos más tarde; luego Paola dirige la mano completa. Choi inunda los pantanos blanquecinos. Se abrazan, desesperadas y en pleno besuqueo. Se consuelan. Porque quizás, el acto ha sido tan tierno, tan intenso, que ambas sospechan en la posibilidad de haber llorado (Arroyo Pizarro 2012b, $81,82,83)$.

Me he permitido citar un extenso fragmento del sensual relato porque da cuenta de algunos presupuestos que podrían asumirse como parte del deseo heteronormado y de la performatividad masculina (las órdenes, el deseo de dominación, el papel activo de una de las partes, la penetración anal que no es recíproca) pero que al explorarse desde el deseo lésbico obtienen algunas pequeñas/grandes transgresiones (la ternura, el placer consensuado, la complicidad). Si volvemos a Lorde, en cuanto a la cuestión de la dominación y un tipo de performatividad sexual ¿qué pensar de esta forma consensuada de dominación erótica lesbiana? ¿Qué decir de la penetración anal y el fisting como propiedad del acto lesbiano? ¿Cómo no encontrar algo de amor en esta dominación? En cuando a esto, Kelly Pereneth propone pensar el ano "como una cavidad experiencial" (2018, 324) que, para tener prácticas políticas resistentes, debe ser entendido no como patrimonio del hombre patriarca heterosexual (incluso del hombre gay). Para ella, la recuperación de ciertas cavidades implica una forma de emancipación corporal guiada por una suerte de feminismo cuir; cuestión que, en su caso, no impide su intersección "lesbiana-afro-cuerpo-migrante" (326), localizada en América Latina.

Repensar las prácticas lésbicas y profundamente eróticas en la literatura permite entender, pues, que Arroyo Pizarro está conectada con la crítica queer; y que, de hecho, sus textos son parte de ese desperdigado e inestable pensamiento que desde ciertas tensiones con el feminismo y los movimientos de la diversidad sexual, ha permitido ensamblar propuestas políticas interesantes para repensar los cuerpos y sus representaciones en 
KİPUS 44, julio-diciembre 2018

América Latina añadiendo a sus anales algo de clase, de etnia, de colonialidad y sobre todo de un complejo y sobrecogedor amor.

\section{EPÍLOGO. HACIA UNA ENTIDAD \\ ESTRATÉGICA DENTRO Y FUERA DEL TEXTO}

las Negras es un libro hábil, que atrincherado en ciertos archivos corporales, busca hacer una crítica antirracista y anticolonial, usando como personajes y narradoras a las mujeres esclavizadas negras del Caribe que articulan un cuerpo que es a la vez un territorio. Otras obras como Caparazones o Lesbianas en clave caribeña obedecen a otro afán, el de expresar formas-otras de ejercicio corporal, en las que el deseo lésbico se disidentifica de formas hegemónicas del amor lésbico, para pensar en un amor cuir. Así, es posible entender cómo la autora, sin salirse del camino del género, esboza dos proyectos ético-estéticos diversos -el uno más identitario y el otro más revisionista de la identidad- que dialogan con diversas formas políticas contemporáneas de construcción subjetiva.

Desde una perspectiva autorial es posible rastrear también estos dos proyectos que, de alguna forma, mezclan vida y obra y que permiten dar un lugar de enunciación, un motor explicativo encarnado a estos textos. En una entrevista de 2014, Yolanda Arroyo Pizarro comentaba:

He sentido el racismo. Me han dicho abiertamente y muy públicamente que ser negra, y escribir de negras y negros, no hace literatura, no hace cultura. Una mujer blanca, aburguesada, que pertenece al mundo de la literatura incluso, me pidió que dejara de escribir sobre raza porque el asunto, según ella, faltaba el respeto al blanco [...] En una ocasión visité un Centro LGBT en Londres, en el que se nos trató muy mal, a mí y a mi compañera Zulma, por ser puertorriqueñas. Así que las exclusiones no son inherentes del opresor. En muchos casos, el opresor recibe la ayuda voluntaria de cómplices dentro de la misma comunidad de oprimidos (Afroméminas 2014).

Por otro lado, en su texto La Macacoa, bitácora escritural de la autora, escrita en el año 2011, comenta lo siguiente:

No soy negra. Me rehúso a asumir la negritud si estoy destinada a narrar única y exclusivamente el mundo desde esa esfera. No soy negra desde 
ese puerto. Me rehúso a asumir los espacios literarios inherentes al color de la epidermis, si eso implica que no tengo otra opción. No deseo que la crítica, la academia, los agentes literarios, los escritores, blancos, mestizos, negros que me rodean me lo pregunten. Me hastía que lo cuestionen, que lo sugieran o me lo traten de imponer. No soy negra. No soy mujer. Ni soy lesbiana, ni divorciada, ni buena gente o intelectual. No soy lo correcto, ni lo incorrecto. Soy un caleidoscopio de posturas, opiniones, opciones, y madeja de decisiones que funcionan, únicamente, en el momento histórico de la ventana del tiempo oportuno $x, y, z$. No soy negra, y a la sazón tampoco madre, acaso ente. No soy clitórica, ni fálica, ni masturbadora o vengativa. No soy bembona ni rapada, ni ex heterosexual, ni fuera del clóset, ni rebelde, o activista o transgresora, si eso es lo que se espera. Soy lo que no se espera. Y tampoco eso soy $(2011,116)$.

Quiero concluir este artículo, con estas dos declaraciones de Arroyo Pizarro, aparentemente contradictorias que, en realidad, dan cuenta de las múltiples posibilidades y agenciabilidades del cuerpo, así como de estos salvajes y fructíferos años en los que los movimientos sociales y las teorías por la liberación y no discriminación sexual, han ido, uno tras/encima/ en contra de otro, moldeando subjetividades que han dejado su rúbrica en los textos literarios latinoamericanos. Me parece que, justamente, para entender los estratégicos cambios narrativos en la autora hay que ubicarla entre ambos fragmentos citados, en una fisura abierta por su propia realidad como negra, puertorriqueña y lesbiana/cuir. Desde allí es que es posible defender la memoria de las mujeres negras esclavizadas en el Caribe, pero también cuestionar la fijeza identitaria que transita por el deseo, la nacionalidad, la colonialidad, la clase. Este posicionamiento político clave apunta a una re-construcción subjetiva no solo a través de la escritura sino a través de la propia carne autorial en la que el agenciamiento negro y antirracista puede convivir con lesbianas, o algo parecido, en constante construcción en el contexto caribeño. Autora y texto, de cualquier forma, amalgaman un interesante legado para la región que revela cómo los sugerentes modelos estéticos en el inicio del siglo XXI han estado modulados por los cambiantes discursos en torno al cuerpo. * 
KİPUS 44, julio-diciembre 2018

\section{Bibliografía}

Afroféminas. 2104. "Entrevista con la escritora Yolanda Arroyo Pizarro". 〈https: //afrofeminas.com/2014/04/01/entrevista-con-la-escritora-yolanda-arroyo-pizarro/>.

Aínsa, Fernando. 2003. “¿Jardín del Edén o infierno verde? Naturaleza y paisaje en la novela de la selva América". Cahiers du CRICCAL: 21-37.

Arboleda Ríos, Paola. 2011. “¿Ser o estar queer en Latinoamérica? El devenir emancipador en Lemebel, Perlongher y Arenas". Íconos. Revista de Ciencias Sociales. n. ${ }^{\circ}$ 39: 111-122.

Arroyo Pizarro, Yolanda. 2010. Caparazones. Barcelona: Egales.

-.2011. La Macacoa. Vivir la creación literaria. Puerto Rico: Boreales.

—. 2012a. "Matronas". En las Negras. Puerto Rico: Boreales.

—. 2012a. "Saeta". En las Negras. Puerto Rico: Boreales.

—. 2012a. "Wanwe". En las Negras. Puerto Rico: Boreales.

—. 2012b. "Asian Jelly". En Lesbianas en clave caribeña. Barcelona: Egales.

- 2012b. "Chévere un mafioso". En Lesbianas en clave caribeña. Barcelona: Egales.

—. 2012b. "Fahrenheit". En Lesbianas en clave caribeña. Barcelona: Egales.

—. 2012b. "Poliarmonía del Caribe". En Lesbianas en clave caribeña. Barcelona: Egales.

De Lauretis, Teresa. 1994. "Habit Changes”. Differences: a Journal of Feminist Cultural Studies. n. ${ }^{\circ}$ 6: 296-313.

Decena, Carlos. 2014. "Sujetos Tácitos”. En Diego Falconí, Santiago Castellanos, María Amelia Viteri, editores. Resentir lo queer en América Latina: diálogos desde/con el Sur. Barcelona: Egales, 217-240.

Espinosa-Miñoso, Yuderkys. 2014. "Una crítica descolonial a la epistemología feminista crítica”. El Cotidiano. n. ${ }^{\circ}$ 184: 7-12.

Falconí Trávez, Diego. 2016. "Puerto Rico erizando mi piel. Intertextos/intercuerpos lordeanos en la narrativa de Yolanda Arroyo Pizarro". Letras femeninas. n. ${ }^{\circ} 42(1): 55-73$.

Gómez Grijalva, Dorotea. 2012. "Mi cuerpo es un territorio político". En Voces Descolonizadoras. Cuaderno 1. México: Brecha Lésbica.

Halberstam, Judith. 2008. Masculinidad femenina. Barcelona: Egales.

Halpering, David. 2014. How to be gay. Harvard: Harvard University Press.

Jeffreys, Sheila. 1996. La herejía lesbiana: una perspectiva feminista de la revolución sexual lesbiana. Valencia: Cátedra.

Kristeva, Julia. 1985. Poderes de la perversión. México: Siglo XXI.

Maldonado-Torres, Nelson. 2007. "Sobre la colonialidad del ser: contribuciones al desarrollo de un concepto”. En Santiago Castro Gómez y Ramón Grosfoguel, editores. El giro decolonial. Reflexiones para una diversidad epistémica más allá del capitalismo global. Bogotá: Iesco-Pensar-Siglo del Hombre Editores. 127-167. 
Mogrovejo, Norma. 2011. "Lo queer en América Latina. ¿Lucha identitaria, post-identitaria, asimilacionista o neo-colonial?”. En Daniel Balderston y Arturo Matute Castro, compiladores. Cartografía queer: sexualidades + activismo LGBT en América Latina. Pittsburg: Universidad de Pittsburg.

Muñoz, José Esteban. 1999. Disidentifications: Queers of Color and the Performance of Politics. Minneapolis: University of Minesota Press.

Pereneth, Kelly. 2018. "Cavidades fijas: género-ironizado agujeros lésbicos. Intersecciones corporales y diva-cagaciones sobre las identidades sexuales". En Diego Falconí, editor. Inflexión marica. Escrituras del descalabro gay en América Latina. Barcelona: Egales.

Pollock, Griselda. 2007. "La heroína y la creación de un canon feminista". En Karen Cordero Reiman e Inda Sáenz. Crítica feminista en la teoría e historia del arte. Ciudad de México: Universidad Iberoamericana. 161-196.

Ramos Rosado, Marie. 2012. "Mayra Santos Febres, Yvonne Denis Rosario y Yolanda Arroyo Pizarro: narradoras afrodescendientes que desafían jerarquías de poder". TINKUY. n. ${ }^{\circ}$ 18: 185-191.

Rodríguez, Juana María. 2016. “Gesto a tiempo de mambo". Posts. n. ${ }^{\circ} 2:$ 22-73. Wittig, Monique. 1977. El deseo lesbiano. Valencia: Pre-textos. 